\title{
science \\ Review of the Board of Editors in the Life Sciences certification examination
}

\author{
Yunhoe Kim \\ Research Institute of Asian Women, Sookmyung Women's University, Seoul, Korea
}

The Board of Editors in the Life Sciences (BELS) certification examination was held by the BELS at the University of Seoul on December 1, 2018 (Fig. 1). It has not been conducted in last 4 years since 2014 in Korea. BELS is a specialized institution established in the United States in 1991 to evaluate the quality of manuscript editors (MEs) in the field of life sciences. It has fostered professional MEs in the life sciences by holding examinations in the United States, Asian countries, and European Medical Writers Association.

Since May, the Korean Council of Science Editors has conducted elementary and intermediate-level training course for MEs, and some of those who completed the course took this examination. Those who took the exam had to solve 106 questions within 3 hours. There were various types of questions, ranging from knowledge of academic journals overall to manuscript-editing practices, but most of them were about substantive editing. Above all, the BELS examination requires academic knowledge of the life sciences, a thorough understanding of English grammar, and training in scientific writing. Therefore, those who are only responsible for the administrative tasks related to academic journal publication and reviews, but who entrust a specialized agency with editing and proofreading despite being an associate editor or ME, would not be able to take the examination. The BELS examination concentrates heavily on editing ability, so it requires specialized training and effort from domestic MEs who do not speak English as their native language.

While preparing for the examination, I had to read a vast amount of data and relevant books, which were helpful to me, personally, regardless of the examination result. In particular, the intermediate-level course for MEs, which was hosted by Korean Council of Science Editors, made me address the necessities of grammar, such as rules for editing, punctuation for style, and the composition of tables and graphs, which were very useful. I would recommend this examination for those who manage the editing and proofreading at a society or specialized

Received: January 25, 2019 Accepted: January 31, 2019

Correspondence to Yunhoe Kim gyusoo@sm.ac.kr

ORCID

Yunhoe Kim

https://orcid.org/0000-0002-4075-8268 institute and want to be recognized as a certified international ME expert in the field of life sciences. Unfortunately, however, it is not guaranteed that the BELS examination will be held annually in Korea, despite its popularity with both domestic MEs and foreigners, many of whom took it in Korea because it was unavailable in their countries. Thus, even if you want to take this examination, you cannot assume that you can register for it in Korea whenever you want. You should check the schedule calendar carefully on the BELS website and see the country and region you can visit (Table 1). 


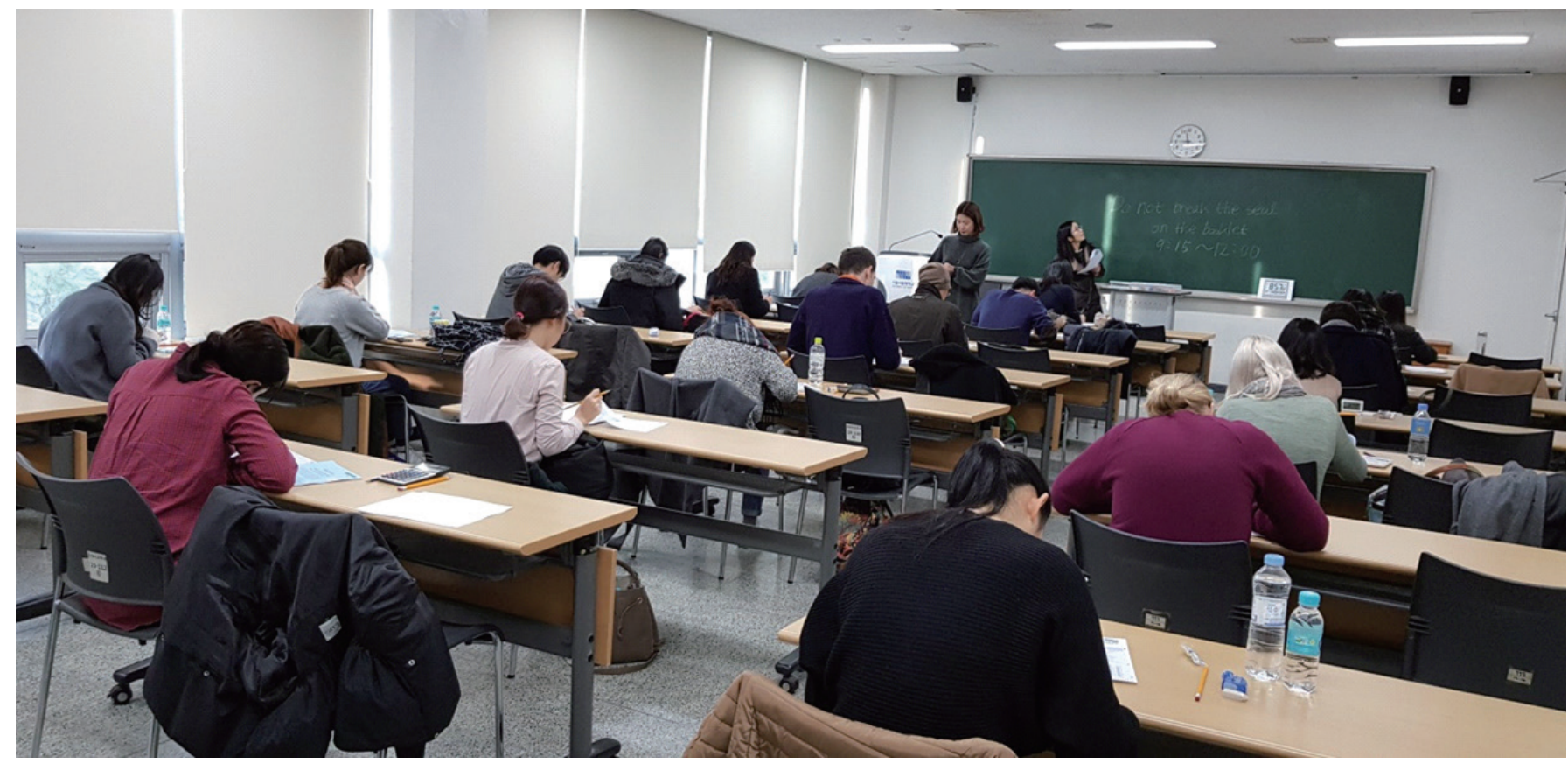

Fig. 1. Photo of Board of Editors in the Life Sciences examinees in Korea (December 1, 2018).

Table 1. Board of Editors in the Life Sciences BELS Ccertification Eexaminations in 2019

\begin{tabular}{|c|c|c|c|c|c|}
\hline Date & Day & Time & City & Site & Register by \\
\hline February 3, 2019 & Sunday & 1:00 p.m.-4:00 p.m. & Mumbai, India & $\begin{array}{l}\text { M. L. Dahanukar College, Dixit Road, } \\
\text { Vile-Parle (East), Mumbai - } 400057 \text { Maharashtra }\end{array}$ & January 13, 2019 \\
\hline March 16, 2019 & Saturday & 1:00 p.m.-4:00 p.m. & Dallas, TX & Meadows Conference Center, 2900 Live Oak Street & February 23, 2019 \\
\hline May 4, 2019 & Saturday & 1:00 p.m.-4:00 p.m. & Columbus, $\mathrm{OH}$ & Hyatt Regency & April 13, 2019 \\
\hline November 6, 2019 & Wednesday & 9:00 a.m.-12:00 noon & San Diego, CA & Sheraton San Diego Hotel and Marina & October 16, 2019 \\
\hline
\end{tabular}

Adapted from https://bels.memberclicks.net/assets/docs/2019\%20Calendar\%20v.6.pdf.

While preparing for the BELS examination, I encountered the following sentence: "Remember that, as writers and editors, it's our job to make our materials clear, not the readers' job to figure out what we meant." In other words, it can be editors' fault rather than readers' fault if readers of an academic journal do not understand articles. If you are preparing for the BELS examination, you should remember that the role of the ME is to make articles clear and easy to understand.

\section{Conflict of Interest}

No potential conflict of interest relevant to this article was reported. 